\title{
Autism Spectrum Disorders in Gender Dysphoric Children and Adolescents
}

\author{
Annelou L. C. de Vries • Ilse L. J. Noens • \\ Peggy T. Cohen-Kettenis - Ina A. van Berckelaer-Onnes • \\ Theo A. Doreleijers
}

Published online: 22 January 2010

(c) The Author(s) 2010. This article is published with open access at Springerlink.com

\begin{abstract}
Only case reports have described the co-occurrence of gender identity disorder (GID) and autism spectrum disorders (ASD). This study examined this co-occurrence using a systematic approach. Children and adolescents (115 boys and 89 girls, mean age 10.8, $\mathrm{SD}=3.58)$ referred to a gender identity clinic received a standardized assessment during which a GID diagnosis was made and ASD suspected cases were identified. The Dutch version of the Diagnostic Interview for Social and Communication Disorders (10th rev., DISCO-10) was administered to ascertain ASD classifications. The incidence of ASD in this sample of children and adolescents was 7.8\% ( $n=16$ ). Clinicians should be aware of co-occurring ASD and GID and the challenges it generates in clinical management.
\end{abstract}

Keywords Autism spectrum disorder .

Gender identity disorder $\cdot$ Co-occurrence $\cdot$ Incidence

A. L. C. de Vries $(\bowtie) \cdot$ T. A. Doreleijers

Department of Child and Adolescent Psychiatry, VU University

Medical Center, PO Box 7057, 1007 MB Amsterdam,

The Netherlands

e-mail: alc.devries@vumc.nl

I. L. J. Noens

Child Welfare and Disabilities, Department of Educational

Sciences, Katholieke Universiteit Leuven, Leuven, Belgium

P. T. Cohen-Kettenis

Department of Medical Psychology, VU University Medical

Center, Amsterdam, Netherlands

I. A. van Berckelaer-Onnes

Department of Educational Sciences, Leiden University, Leiden,

The Netherlands
Gender dysphoria is the distress resulting from an incongruence between assigned and experienced gender. The official DSM-IV-TR diagnosis of gender identity disorder (GID) is characterized by a strong and persistent crossgender identification as well as a persistent discomfort with one's biological sex and a sense of inappropriateness in the gender role of that sex (American Psychiatric Association 2000). Estimates of GID in adults range from 1:10,000 to 1:20,000 in men and 1:30,000 to 1:50,000 in women (for a review, see Zucker and Lawrence 2009). Prevalence rates of autism spectrum disorder (ASD) in various recent studies are generally in the range of 60 per 10,000 (for a review, see Fombonne 2005) although some studies report a prevalence above $1 \%$ (e.g. Baird et al. 2006). With the reported prevalence rates of ASD and GID, the random cooccurrence of both would be extremely rare. However, gender identity clinics are now reporting an overrepresentation of individuals with ASD in their referrals (Robinow and Knudson 2005). The putative co-occurrence is not only relevant for diagnostic and clinical management reasons, but it also raises important theoretical questions if, indeed, there would be evidence for co-occurrence.

To date, however, studies using systematic measures on this co-occurrence have not been published. The literature on the co-occurrence of ASD and gender dysphoria consists of seven papers describing nine case histories of individuals with ASD and concomitant gender identity problems, mostly children (Gallucci et al. 2005; Kraemer et al. 2005; Landen and Rasmussen 1997; Mukaddes 2002; Perera et al. 2003; Tateno et al. 2008; Williams et al. 1996). Authors show various perspectives in how to understand the co-occurrence of ASD and gender dysphoria. Some of them state that gender dysphoria and autism can be truly co-occurring disorders (Mukaddes 2002; Tateno et al. 2008). Others assume that cross gender 
behavior results from the inherent predisposition toward unusual interests characteristic of ASD (Williams et al. 1996). It is also suggested that gender dysphoria in individuals with ASD may be considered an obsessive compulsive disorder, separate from both ASD and GID (Landen and Rasmussen 1997; Perera et al. 2003).

In sum, the co-occurrence of gender dysphoria and ASD is of current clinical interest. This study was conducted to establish the incidence of ASD in gender dysphoric children and adolescents, and to describe the specific clinical characteristics of individuals with both gender dysphoria and ASD.

\section{Method}

\section{Participants}

Participants were 231 children and adolescents who had been referred to the Gender Identity Clinic of the VU University Medical Centre in Amsterdam between April 2004 and October 2007. This is the only clinic in the Netherlands with a multidisciplinary team examining gender dysphoric children and adolescents. Nineteen children and eight adolescents were excluded from the study because they were not able to complete the assessment procedure. Reasons were cessation of the gender identity problems at the time of assessment (in some cases due to the waiting list), or serious other psychopathology making a referral to a local mental health clinics necessary and completing the assessment not possible. This resulted in a study group consisting of 108 children (mean age 8.06, $\mathrm{SD}=1.82$ ) and 96 adolescents (mean age 13.92, $\mathrm{SD}=2.29$ ) consecutively assessed of whom 11 ASD suspected children and 15 ASD suspected adolescents were identified.

\section{Procedure}

All 204 individuals received a standardized clinical assessment, according to the Standards of Care of the World Professional Association for Transgender Health (Meyer et al. 2001). A separate protocol is followed for children under the age of 12 and adolescents between age 12 and 18, respectively. It includes psycho-diagnostic interviews with the child or the adolescent, interviews with the parents about topical functioning as well as the developmental history of the child or adolescent, psychological testing by a trained psychometrist and collection of school information (for a detailed description of the clinical procedure and used instruments, see Cohen-Kettenis 2006).

Persistence of the gender dysphoria of the children and adolescents with ASD was evaluated in 2008 or 2009, which was at least 1 year and in some cases 4 years after the initial assessment. The clinical files were evaluated for those individuals who still attended the gender identity clinic. If no recent information was available, the parents were called.

The study was approved by the Ethical committee of the VU University Medical Centre. Informed consent was obtained from the parents as well as the adolescents age 12 and older.

Measures

\section{Intelligence}

IQ was assessed by use of the Dutch versions of the Wechsler Intelligence Scale for Children or the Wechsler Adult Intelligence Scale depending on the participant's age (Wechsler 1997; Wechsler et al. 2002).

\section{Autism Spectrum Disorders}

ASD suspected children and adolescents were identified by discussing potential characteristics of ASD of all new referrals in weekly team meetings. Further diagnostic assessment for ASD was considered when either earlier reports suggested an ASD or the examining psychologist or psychiatrist (first author AV) suspected an ASD. Parents or caregivers of ASD suspected individuals were then invited for a diagnostic ASD interview. ASD diagnoses were confirmed using the Dutch version of the Diagnostic Interview for Social and Communication Disorders-10th revision (DISCO-10 Wing 1999; Dutch version Van Berckelaer-Onnes et al. 2003). The DISCO-10 was chosen for its particular effectiveness for diagnosing disorders within the broader autism spectrum. The DISCO is a semistructured $2-4 \mathrm{~h}$ interview. Its algorithms enable to investigate whether the necessary criteria of different diagnostic systems for ASD are met. During the interview, answers to over 300 questions are coded for computer entry. Inter-rater reliability for the items in the DISCO interview were high, with a kappa coefficient or intra-class correlation at .75 or higher achieved for over $80 \%$ of the interview items (Wing et al. 2002). The DISCO-10 was administered by two of the authors (IvBO or IN), who were formally trained in the use of the DISCO-10. The diagnostic algorithms that were used in the current study reflect DSM-IV-TR and ICD-10 criteria for Pervasive Developmental Disorders (American Psychiatric Association 2000; World Health Organization 1993). From the DISCO-10, one obtains an 'ever' diagnosis, which is retrospective, as well as a 'current' diagnosis, with 'ever' including 'current'. In the current paper, only 'ever' diagnoses are reported. 


\section{Gender Dysphoria}

Based on the DSM-IV-TR criteria, children and adolescents were classified as GID, the subthreshold GID not otherwise specified (GID-NOS) or no GID (APA 2000). Additionally, the list of Dimensional Diagnostic Criteria of the GID (DDC-GID) was used. This list was constructed by one of the authors (PCK) and describes DSM-IV-TR subcriteria of the GID A and B criterions (cross-gender identification and discomfort with his or her sex, respectively). Each sub-criterion can be rated dimensionally with regard to strength, persistence, and duration. Whether criterion $\mathrm{A}$ and $\mathrm{B}$ are fulfilled remains a clinical decision. Criterion $\mathrm{C}$ is an exclusion criterion (no intersex condition). Criterion $\mathrm{D}$ (the behavior should reveal clinically significant distress or impairment) may range from no distress, mild distress to strong distress (or unclear) in social, occupational, family or other areas of functioning. GID diagnostic criteria of the individuals who had received a DISCO interview were specified (e.g. sexual orientation, history of childhood GID) by making use of the DDC-GID. Clinical consensus was met for each case by the first author (AV) and one of the other members of the gender identity clinic team for children and adolescents.

\section{Analyses}

Incidence of ASD in the referred children and adolescents was calculated by the percentage of DISCO-confirmed ASD diagnoses in the total number of referrals of children and adolescents separately as well as in the combined sample. Fisher exact tests were used to analyze differences in incidence of individuals with ASD in individuals with GID compared to individuals with GID-NOS.

Independent $t$-tests were used to ascertain differences in age and IQ between all referred children and adolescents with and without an ASD.

Specific clinical characteristics and follow-up reports of the gender dysphoria were collected from the clinical files and described with regard to GID classification, ASD classification, age of onset of GID, the persistence of a GID diagnosis at follow-up, and, for the adolescents, sexual orientation.

\section{Results}

\section{Children}

According to the DISCO algorithms, seven (six boys, one girl) of the 11 ASD suspected children had ASD. The incidence of ASD in all 108 assessed children (70 boys, 38 girls) was $6.4 \%(n=7)$. The incidence of ASD in the 52 children with a GID diagnosis was $1.9 \%(n=1)$, which was significantly lower than the incidence of $13 \%(n=6)$ of ASD in the 45 children with a GID-NOS (gender identity disorder not otherwise specified) diagnosis $(p<.05)$. In the 11 children with no GID diagnosis, none had ASD.

The mean age of children with ASD $(M=9.1, \mathrm{SE}=0$ .47) was not significantly different from the children without $\operatorname{ASD}(M=8.0, \mathrm{SE}=0.18, t=-1.63, d f=106$, $p=0.11)$. The mean IQ $(M=82.00, \mathrm{SE}=3.74)$ of the children with ASD was significantly lower compared to the mean IQ of the children without ASD $(M=103.92$, $\mathrm{SE}=1.18, t=4.88, d f=101, p<.001)$.

Table 1 presents the specific clinical characteristics of children with co-occurring GID and ASD. Most remarkable results were that six of the seven children with GID and ASD were male, all seven children fulfilled the strict criteria of autistic disorder, and in six of the seven children the gender dysphoria had alleviated when outcome was evaluated at least 1 year after the initial assessment.

\section{Adolescents}

According to the DISCO algorithms, nine (six boys, three girls) of the 15 ASD suspected adolescents had ASD. The incidence of ASD in all 96 assessed adolescents (45 boys, 51 girls) was $9.4 \%(n=9)$. The incidence of ASD in the 77 adolescents with a GID diagnosis was $6.5 \%(n=5)$, which was significantly lower than the incidence of $37.5 \%$ $(n=3)$ of ASD in the eight adolescents with a GID-NOS diagnosis $(p<.05)$. In the 11 adolescents with no GID diagnosis, one suffered from ASD and transvestic fetishism but no gender dysphoria.

The mean age of the adolescents with ASD $(M=15.41$, $\mathrm{SE}=0.65)$ was significantly higher than the adolescents without ASD $(M=13.77, \quad \mathrm{SE}=0.24, \quad t=-2.09$, $d f=94, p<.05)$. The mean IQ of adolescents with an ASD $(M=89.88, \mathrm{SE}=5.52)$ was not significantly different from the mean IQ of the adolescents without ASD $(M=96.67, \mathrm{SE}=1.72, t=1.20, d f=85, p=.23)$.

Table 2 presents the specific clinical characteristics of the adolescents with co-occurring GID and ASD. Most remarkable results were that six of the nine adolescents fulfilled the strict criteria of autistic disorder (the other three Asperger's disorder), four adolescents were eligible for sex reassignment, of whom two were female, but none of them as yet had their sex reassignment surgery. Two adolescents dropped out of care, of whom one was reported to have sex reassignment surgery abroad.

\section{Children and Adolescents Combined}

The incidence of ASD in the combined sample of children and adolescents was $7.8 \%$ (204 individuals, 115 boys and 
Table 1 Demographic and clinical characteristics of children diagnosed with both GID and ASD

\begin{tabular}{|c|c|c|c|c|c|c|c|c|}
\hline No & Sex & Age & IQ & $\begin{array}{l}\text { ASD } \\
\text { classification }\end{array}$ & $\begin{array}{l}\text { GID } \\
\text { classification }\end{array}$ & GID symptoms: history & At time of assessment & Follow-up \\
\hline 1 & Boy & 7 & 88 & Autism $^{\mathrm{a}}$ & GID-NOS $^{\mathrm{b}}$ & $\begin{array}{l}\text { From toddler age on, } \\
\text { fascinated by jewelry, } \\
\text { girls' toys, female bodies } \\
\text { (mother) }\end{array}$ & $\begin{array}{l}\text { Seems to get sexually aroused } \\
\text { by touching women's breasts } \\
\text { and dressing up }\end{array}$ & $\begin{array}{c}\text { No GID }{ }^{c} \text {; at age } 10, \text { no female } \\
\text { preferences anymore, still } \\
\text { attracted to female bodies } \\
\text { with some sexual arousal }\end{array}$ \\
\hline 2 & Boy & 8 & 108 & Autism & GID-NOS & $\begin{array}{l}\text { Obsessive dressing up as a } \\
\text { girl, wearing high heels, } \\
\text { interested in make-up }\end{array}$ & $\begin{array}{l}\text { No further interests in girls' } \\
\text { toys, no wish to be a girl }\end{array}$ & $\begin{array}{l}\text { No GID; at age } 10 \text {, obsessive } \\
\text { dressing up reduced by } \\
\text { behavioral program, still } \\
\text { wearing high heels }\end{array}$ \\
\hline 3 & Boy & 9 & 69 & Autism & GID-NOS & $\begin{array}{l}\text { From toddler age on, } \\
\text { playing with dolls, } \\
\text { dressing-up in robes, high } \\
\text { heels, make-up }\end{array}$ & $\begin{array}{l}\text { Likes cars as well, but rather } \\
\text { wants to be a girl }\end{array}$ & $\begin{array}{l}\text { No GID; at age } 12 \text { happy } \\
\text { being a boy, but still female } \\
\text { behavior resulting in } \\
\text { difficulties with peers }\end{array}$ \\
\hline 4 & Boy & 9 & 75 & Autism & GID-NOS & $\begin{array}{l}\text { From toddler age on } \\
\text { fascinated by mermaids, } \\
\text { fairy tales, dolls, ballet, } \\
\text { dressing-up, did not like } \\
\text { his penis }\end{array}$ & $\begin{array}{l}\text { No interest in dolls and } \\
\text { dressing up any more, now } \\
\text { fascinated by nature and } \\
\text { culture, still liking ballet and } \\
\text { theatre }\end{array}$ & $\begin{array}{l}\text { No GID; at age } 10 \text {, no explicit } \\
\text { wish to be a girl }\end{array}$ \\
\hline 5 & Boy & 10 & 95 & Autism & GID & $\begin{array}{l}\text { From toddler age on } \\
\text { interested in dolls, } \\
\text { dressing up, pink, wishes } \\
\text { to be a girl }\end{array}$ & $\begin{array}{l}\text { Wearing girl's clothes } \\
\text { restricted, but looks and } \\
\text { behaves like a girl with long } \\
\text { hair and bright colored } \\
\text { clothes }\end{array}$ & $\begin{array}{l}\text { Persisting GID; at age } 12 \text {, } \\
\text { explicit wish to be a girl }\end{array}$ \\
\hline 6 & Boy & 10 & 72 & Autism & GID-NOS & $\begin{array}{l}\text { From toddler age on, } \\
\text { fascinated by music, } \\
\text { dancing, dressing up, } \\
\text { glitter, long hair, girls' } \\
\text { clothes }\end{array}$ & $\begin{array}{l}\text { Still interested in music and } \\
\text { girls' clothes, but does not } \\
\text { want to be a girl }\end{array}$ & $\begin{array}{l}\text { No GID; at age } 12, \text { no female } \\
\text { preferences, likes music, } \\
\text { happy being a boy }\end{array}$ \\
\hline 7 & Girl & 10 & 81 & Autism & GID-NOS & $\begin{array}{l}\text { From toddler age on, only } \\
\text { wearing trousers, short } \\
\text { hair, playing with boys' } \\
\text { toys }\end{array}$ & $\begin{array}{l}\text { Hates being a girl, but being } \\
\text { called a boy irritates her, } \\
\text { anxiety about any medical } \\
\text { intervention }\end{array}$ & $\begin{array}{l}\text { No GID; at age } 13 \text {, happy } \\
\text { being a 'tomboy' girl }\end{array}$ \\
\hline
\end{tabular}

\footnotetext{
a Autism autistic disorder

b GID-NOS gender identity disorder not otherwise specified

c GID gender identity disorder
}

89 , mean age 10.8, $\mathrm{SD}=3.58$ ). The incidence of ASD in the combined sample of 129 individuals with a GID diagnosis was $4.7 \%(n=6)$, which is significantly lower compared to the incidence of $17.0 \%(n=9)$ of ASD in 53 individuals with a GID-NOS diagnosis $(p<.05)$.

\section{Discussion}

The incidence of $7.8 \%$ ASD in gender identity clinic referred children and adolescents is ten times higher than the prevalence of $0.6-1 \%$ of ASD in the general population (Baird et al. 2006; Fombonne 2005). This important finding confirms the clinical impression that ASD occurs more frequently in gender dysphoric individuals than expected by chance.

Most remarkable in the clinical presentation of individuals with co-occurring GID and ASD in this study was the considerable diversity concerning: sex (both male and female), GID classification (GID, GID-NOS, transvestic fetishism), ASD classification (autistic disorder, Asperger's disorder), age of onset of GID (before or after puberty), and the persistence of cross-sex behavior (ceasing or persisting).

The overrepresentation of males in our study is in accordance with the epidemiology of both ASD and GID (Fombonne 2005; Zucker and Lawrence 2009). Studies in girls with congenital adrenal hyperplasia, who are prenatally exposed to high levels of testosterone, showed that they had more traits of ASD than controls and some developed gender identity problems (Dessens et al. 2005; Knickmeyer et al. 2006). However, the idea that prenatal testosterone may be involved in the vulnerability to both ASD and gender dysphoria, seems not applicable in our sample. In that case, especially girls with ASD would have been susceptible to develop gender dysphoria. In addition, 
Table 2 Demographic and clinical characteristics of adolescents diagnosed with both GID and ASD

\begin{tabular}{|c|c|c|c|c|c|c|c|c|}
\hline No & Sex & Age & IQ & $\begin{array}{l}\text { ASD } \\
\text { classification }\end{array}$ & $\begin{array}{l}\text { GID } \\
\text { classification }\end{array}$ & $\begin{array}{l}\text { GID } \\
\text { symptoms: } \\
\text { history }\end{array}$ & At time of assessment & Follow-up \\
\hline 1 & Girl & 12 & 82 & Asperger's ${ }^{a}$ & GID-NOS $^{\mathrm{b}}$ & $\begin{array}{l}\text { Childhood } \\
\text { GID }\end{array}$ & Sexually attracted to males & $\begin{array}{l}\text { Not eligible for } \mathrm{SR}^{\mathrm{c}} \text {; happy being a } \\
\text { 'tomboy' after counseling }\end{array}$ \\
\hline 2 & Boy & 13 & 92 & Autism $^{\mathrm{d}}$ & $\mathrm{GID}^{\mathrm{e}}$ & $\begin{array}{l}\text { Childhood } \\
\text { GID }\end{array}$ & $\begin{array}{l}\text { Sexually attracted to neither boys nor } \\
\text { girls, no sexual arousal while cross- } \\
\text { dressing }\end{array}$ & $\begin{array}{l}\text { Eligible for SR; delayed start puberty } \\
\text { suppression, waiting to start cross- } \\
\text { sex hormones }\end{array}$ \\
\hline 3 & Boy & 14 & 106 & Asperger's & GID & $\begin{array}{l}\text { Childhood } \\
\text { GID }\end{array}$ & $\begin{array}{l}\text { Sexually attracted to boys, no sexual } \\
\text { arousal while cross-dressing }\end{array}$ & $\begin{array}{l}\text { Eligible for SR; delayed start puberty } \\
\text { suppression, now on cross-sex } \\
\text { hormones }\end{array}$ \\
\hline 4 & Boy & 15 & 62 & Autism & $\mathrm{TF}^{\mathrm{f}}$ & $\begin{array}{l}\text { No } \\
\text { childhood } \\
\text { GID }\end{array}$ & $\begin{array}{l}\text { Sexually attracted to both girls and } \\
\text { boys, sexual arousal while cross- } \\
\text { dressing }\end{array}$ & $\begin{array}{l}\text { Not eligible for SR; referred for } \\
\text { cognitive behavioral therapy } \\
\text { around disturbing sexual arousal }\end{array}$ \\
\hline 5 & Boy & 16 & $\mathrm{NA}^{\mathrm{g}}$ & Autism & GID-NOS & $\begin{array}{l}\text { Childhood } \\
\text { GID-NOS }\end{array}$ & $\begin{array}{l}\text { Sexually attracted to homosexual boys, } \\
\text { no sexual arousal while cross- } \\
\text { dressing }\end{array}$ & Dropped out of care \\
\hline 6 & Boy & 16 & 104 & Autism & GID-NOS & $\begin{array}{l}\text { No } \\
\text { childhood } \\
\text { GID }\end{array}$ & $\begin{array}{l}\text { Sexually attracted to girls, sometimes } \\
\text { sexual arousal but no sexual } \\
\text { motivation while cross-dressing }\end{array}$ & $\begin{array}{l}\text { Not eligible for SR; referred for } \\
\text { autism treatment, still strong wish } \\
\text { for SR }\end{array}$ \\
\hline 7 & Girl & 17 & 110 & Asperger's & GID & $\begin{array}{l}\text { Childhood } \\
\text { GID }\end{array}$ & $\begin{array}{l}\text { Sexually attracted to girls, no sexual } \\
\text { arousal while cross-dressing }\end{array}$ & $\begin{array}{l}\text { Eligible for SR; delayed start cross } \\
\text { sex hormones, waiting for } \\
\text { mastectomy }\end{array}$ \\
\hline 8 & Boy & 17 & 81 & Autism & GID & $\begin{array}{l}\text { Childhood } \\
\text { GID }\end{array}$ & $\begin{array}{l}\text { Sexually attracted to girls, no sexual } \\
\text { arousal while cross-dressing }\end{array}$ & $\begin{array}{l}\text { Dropped out of care; unwilling to } \\
\text { assent to treatment plan, got } \\
\text { himself a SR surgery abroad }\end{array}$ \\
\hline 9 & Girl & 18 & 86 & Autism & GID & $\begin{array}{l}\text { Childhood } \\
\text { GID }\end{array}$ & $\begin{array}{l}\text { Sexually attracted to girls, no sexual } \\
\text { arousal while cross-dressing }\end{array}$ & $\begin{array}{l}\text { Eligible for SR, delayed start cross } \\
\text { sex hormones, waiting for } \\
\text { mastectomy }\end{array}$ \\
\hline
\end{tabular}

a Asperger's Asperger's disorder

b GID-NOS gender identity disorder not otherwise specified

c $S R$ sex reassignment

d Autism autistic disorder

e GID gender identity disorder

f $T F$ transvestic fetishism

g NA not available

why gender dysphoria and ASD co-occur in males is unexplained by prenatal androgen exposure. This finding adds to the lack of experimental evidence for a link between low testosterone and GID in males.

Symptoms of GID displayed by individuals with ASD varied substantially. Individuals with an ASD frequently received a GID-NOS diagnosis. GID-NOS appeared to be given when the cross gender behavior and interests were merely subthreshold (mostly in children), or atypical or unrealistic. For example, an adolescent with ASD, who always had the feeling of being different from his peers in childhood, but had no history of childhood cross-gender behavior, became convinced that this feeling of alienation was explained by gender dysphoria. He had the hope that his communication problems would alleviate by taking estrogens. In another adolescent, the cross-gender behavior indicated transvestic fetishism rather than gender dysphoria.
This corresponds with the findings of frequent non-normative sexual interests and behaviors in adolescents and adults with ASD (Hellemans et al. 2007). Feminine interests of many gender dysphoric young boys with ASD concerned soft tissues, glitter, and long hair and could be understood as a preference for specific sensory input typical for ASD.

While almost all adolescents with GID are sexually attracted to individuals of their birth sex (Smith et al. 2005; Wallien and Cohen-Kettenis 2008), the majority of the gender dysphoric adolescents with ASD was sexually attracted to partners of the other sex. This may be clinically relevant since adult transsexuals not sexually attracted to their natal sex show in some studies less satisfactory postoperative functioning compared with birth-sex attracted transsexuals (Smith et al. 2005).

Most individuals with co-occurring gender dysphoria and ASD fulfilled the strict criteria of autistic disorder. For 
several youth with ASD, their ASD-specific rigidity made enduring gender variant feelings extremely difficult to handle. After all, in our society a considerable amount of flexibility is needed to deal with gender variant feelings. Normally developing young children (age 3-5) display more rigidity in gender-related beliefs than older children; this rigidity decreases after the age of five (Ruble et al. 2007). Individuals with ASD may not reach this level of flexibility in their gender development.

In most gender dysphoric children, gender dysphoria will cease when they reach puberty, whereas adolescents with a GID will likely pursue their wish for sex reassignment into adulthood (Cohen-Kettenis and Pfäfflin 2003; Wallien and Cohen-Kettenis 2008; Zucker and Bradley 1995). Likewise, in children under age 12 with co-occurring ASD the gender dysphoria alleviated and in adolescents between age 12 and 18 their GID persisted.

The present findings should be considered in the light of limitations in sampling and assessment. First of all, it is apt to realize that the actual incidence of ASD in gender clinic referred children and adolescents is probably higher than the reported percentage. One of the reasons to assume an underestimation is that some children and adolescents with ASD (as diagnosed elsewhere) were unable to fulfill the assessment procedure due to serious impairment. In other cases, features of ASD were observed, but parents tended to underreport the ASD symptoms in the DISCO-10 interview, as that was not the primary concern about their child. Finally, it was not feasible to administer a DISCO-10 interview to all participants. Clinicians of the gender identity clinic identified suspected cases. Based on the epidemiology of ASD, the majority was expected to fall into the broader spectrum, whereas in this study no pervasive developmental disorder not otherwise specified was classified. This may reflect that our clinicians had a high threshold for suspecting ASD, as their primary focus was gender dysphoria.

Second, the individuals who investigated whether criteria for ASD were met, were aware that the reason for referral was a possible GID. This study was performed at a specialized gender identity clinic, and therefore blinding was not feasible.

Third, we studied a gender identity clinic referred population. Whether the same high incidence of co-occurring ASD and gender dysphoria will also be found in individuals with ASD as primary concern remains unknown and should be of interest for further studies. One might expect milder or more atypical types of gender dysphoria as part of other nonnormative sexual behaviors and interests, as was found in a study of males with ASD (Hellemans et al. 2007).

Third, the categorical DSM-IV-TR classification approach is not appropriate to study more subtle expressions of both ASD and GID. Future studies should focus on dimensional measures and specific cognitive or neuropsychological profiles of individuals with co-occurring gender dysphoria and ASD. For example, the observed rigidity in gender related beliefs in young children may make children with ASD more prone to develop gender dysphoria (Ruble et al. 2007). Furthermore, it seems important to address the broader autism phenotype (clinical traits that are milder but qualitatively similar to the characteristics of autism (Losh et al. 2009) in upcoming studies in a gender identity clinic referred population. It may be that these traits occur more often in gender dysphoric individuals than a full-blown ASD as was found in, for example, children with mood and anxiety disorders and ADHD (Nijmeijer et al. 2009; Pine et al. 2008).

For clinical management, our findings on clinical characteristics of individuals with co-occurring gender dysphoria and ASD have consequences. In all cases described, the diagnostic procedure was extended to disentangle whether the gender dysphoria evolved from a general feeling of being 'different' or a 'core' cross-gender identity. Most helpful seemed an individual approach that took into consideration that rigid and concrete thinking around gender roles and difficulty developing aspects of personal identity may play a part. Concerning sex reassignment, ASD does not have to be a strict exclusion criterion. Only one case study described a woman with an Asperger's disorder who received sex reassignment (Kraemer et al. 2005), although we know of more cases in clinical practice. In our sample, almost half of the adolescents with both ASD and GID started with gender reassignment. Worrisome are the adolescents that dropped out of care, probably finding their own ways to sex reassignment, without psychiatric treatment or medical attention. It remains a challenge to provide individuals with co-occurring gender dysphoria and ASD with proper care.

Acknowledgments This research was supported by a personal grant for the first author from the Netherlands organization for health research and development (ZonMw). The authors thank the study families for participating in this study. Results of this study were presented on the 8th International Meeting for Autism Research being held in Chicago, May 7-9, 2009. The authors report no conflict of interest.

Open Access This article is distributed under the terms of the Creative Commons Attribution Noncommercial License which permits any noncommercial use, distribution, and reproduction in any medium, provided the original author(s) and source are credited.

\section{References}

American Psychiatric Association. (2000). Diagnostic and statistical manual of mental disorders, fourth edition, text revision (4th ed.). Washington, DC: American Psychiatric Association. 
Baird, G., Simonoff, E., Pickles, A., Chandler, S., Loucas, T., Meldrum, D., et al. (2006). Prevalence of disorders of the autism spectrum in a population cohort of children in South Thames: The special needs and autism project (SNAP). Lancet, $368(9531), 210-215$.

Cohen-Kettenis, P. T. (2006). Gender identity disorder. In C. Gillberg, R. Harrington, \& H. C. Steinhausen (Eds.), A clinician's handbook of child and adolescent psychiatry (pp. 695-725). Cambridge: Cambridge University Press.

Cohen-Kettenis, P. T., \& Pfäfflin, F. (2003). Transgenderism and intersexuality in childhood and adolescence (Vol. 46). Thousand Oaks, London, New Delhi: SAGE Publications.

Dessens, A. B., Slijper, F. M., \& Drop, S. L. (2005). Gender dysphoria and gender change in chromosomal females with congenital adrenal hyperplasia. Archives of Sexual Behavior, 34(4), 389-397.

Fombonne, E. (2005). Epidemiology of autistic disorder and other pervasive developmental disorders. Journal of Clinical Psychiatry, 66(Suppl 10), 3-8.

Gallucci, G., Hackerman, F., \& Schmidt, C. W. (2005). Gender identity disorder in an adult male with Asperger's syndrome. Sexuality and Disability, 23(1), 35-40.

Hellemans, H., Colson, K., Verbraeken, C., Vermeiren, R., \& Deboutte, D. (2007). Sexual behavior in high-functioning male adolescents and young adults with autism spectrum disorder. Journal of Autism and Developmental Disorders, 37(2), 260269.

Knickmeyer, R., Baron-Cohen, S., Fane, B. A., Wheelwright, S., Mathews, G. A., Conway, G. S., et al. (2006). Androgens and autistic traits: A study of individuals with congenital adrenal hyperplasia. Hormones and Behavior, 50(1), 148-153.

Kraemer, B., Delsignore, A., Gundelfinger, R., Schnyder, U., \& Hepp, U. (2005). Comorbidity of Asperger syndrome and gender identity disorder. European Child and Adolescent Psychiatry, 14(5), 292-296.

Landen, M., \& Rasmussen, P. (1997). Gender identity disorder in a girl with autism-a case report. European Child and Adolescent Psychiatry, 6(3), 170-173.

Losh, M., Adolphs, R., Poe, M. D., Couture, S., Penn, D., Baranek, G. T., et al. (2009). Neuropsychological profile of autism and the broad autism phenotype. Archives of General Psychiatry, 66(5), $518-526$.

Meyer, W., Bockting, W. O., Cohen-Kettenis, P. T., Coleman, E., Di Ceglie, D., Devor, H., et al. (2001). Standards of care for gender identity disorders of the Harry Benjamin international gender dysphoria association, 6th edn. Retrieved May 25, 2007, from http://www.wpath.org/.

Mukaddes, N. M. (2002). Gender identity problems in autistic children. Child: Care, Health and Development, 28(6), 529-532.

Nijmeijer, J. S., Hoekstra, P. J., Minderaa, R. B., Buitelaar, J. K., Altink, M. E., Buschgens, C. J., et al. (2009). PDD symptoms in ADHD, an independent familial trait? Journal of Abnormal Child Psychology, 37(3), 443-453.

Perera, H., Gadambanathan, T., \& Weerasiri, S. (2003). Gender identity disorder presenting in a girl with Asperger's disorder and obsessive compulsive disorder. Ceylon Medical Journal, 48(2), 57-58.

Pine, D. S., Guyer, A. E., Goldwin, M., Towbin, K. A., \& Leibenluft, E. (2008). Autism spectrum disorder scale scores in pediatric mood and anxiety disorders. Journal of the American Academy of Child and Adolescent Psychiatry, 47(6), 652-661.

Robinow, O., \& Knudson, G. A. (2005). Asperger's disorder and GID. Paper presented at the XIX Biennial symposium of the Harry Benjamin International Gender Dysphoria Association.

Ruble, D. N., Taylor, L. J., Cyphers, L., Greulich, F. K., Lurye, L. E., \& Shrout, P. E. (2007). The role of gender constancy in early gender development. Child Development, 78(4), 1121-1136.

Smith, Y. L., van Goozen, S. H., Kuiper, A. J., \& Cohen-Kettenis, P. T. (2005). Transsexual subtypes: Clinical and theoretical significance. Psychiatry Research, 137(3), 151-160.

Tateno, M., Tateno, Y., \& Saito, T. (2008). Comorbid childhood gender identity disorder in a boy with Asperger syndrome. Psychiatry and Clinical Neurosciences, 62(2), 238.

Van Berckelaer-Onnes, I., Noens, I., \& Dijkxhoorn, Y. (2003). Diagnostic interview for social and communication disordersHandleiding. Leiden: Universiteit Leiden.

Wallien, M. S., \& Cohen-Kettenis, P. T. (2008). Psychosexual outcome of gender-dysphoric children. Journal of the American Academy of Child and Adolescent Psychiatry, 47(12), 14131423.

Wechsler, D. (1997). Wechsler adult intelligence scale-third edition (WAIS-III), Dutch version (3rd ed.). Lisse, the Netherlands: Swets and Zetlinger.

Wechsler, D., Kort, W., Compaan, E. L., Bleichrodt, N., Resing, W. C. M., \& Schittkatte, M. (2002). Wechsler intelligence scale for children-third edition (WISC-III) (3rd ed.). Lisse: Swets and Zettlinger.

Williams, P. G., Allard, A. M., \& Sears, L. (1996). Case study: Crossgender preoccupations with two male children with autism. Journal of Autism and Developmental Disorders, 26(6), 635642.

Wing, L. (1999). Diagnostic interview for social and communication disorders. Manual. Bromley: Centre for Social and Communication Disorders.

Wing, L., Leekam, S. R., Libby, S. J., Gould, J., \& Larcombe, M. (2002). The diagnostic interview for social and communication disorders: Background, inter-rater reliability and clinical use. Journal of Child Psychology and Psychiatry and Allied Disciplines, 43(3), 307-325.

World Health Organization. (1993). International statistical classification of diseases and related health problems (10th ed.). Geneva: World Health Organization.

Zucker, K. J., \& Bradley, S. (1995). Gender identity disorder and psychosexual problems in children and adolescents. New York: Guilford.

Zucker, K. J., \& Lawrence, A. A. (2009). Epidemiology of gender identity disorder: Recommendations for the standards of care of the world professional association for transgender health. International Journal of Transgenderism, 11, 8-18. 